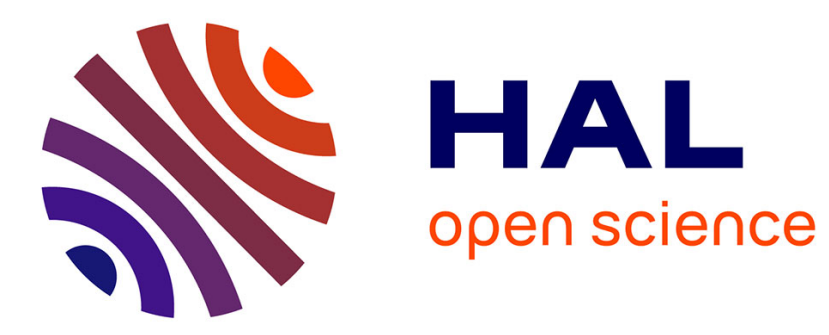

\title{
Semi-empirical Erosion Model with Particle Size and Liquid Water Content Effects for Ice Crystal Icing Simulations
}

Virgile Charton, Jean-Mathieu Senoner, Pierre Trontin, Philippe Villedieu

\section{- To cite this version:}

Virgile Charton, Jean-Mathieu Senoner, Pierre Trontin, Philippe Villedieu. Semi-empirical Erosion Model with Particle Size and Liquid Water Content Effects for Ice Crystal Icing Simulations. AIAA AVIATION 2020, Jun 2020, RENO, United States. 10.2514/6.2020-2827 . hal-02906383

\section{HAL Id: hal-02906383 \\ https://hal.science/hal-02906383}

Submitted on 24 Jul 2020

HAL is a multi-disciplinary open access archive for the deposit and dissemination of scientific research documents, whether they are published or not. The documents may come from teaching and research institutions in France or abroad, or from public or private research centers.
L'archive ouverte pluridisciplinaire HAL, est destinée au dépôt et à la diffusion de documents scientifiques de niveau recherche, publiés ou non, émanant des établissements d'enseignement et de recherche français ou étrangers, des laboratoires publics ou privés. 


\title{
Semi-empirical Erosion Model Revisited with Particle Size and Liquid Water Content Effect for Ice Crystal Icing Numerical Simulation
}

\author{
Virgile Charton \\ Safran Aircraft Engines, F-77550, Moissy-Cramayel, France \\ Jean-Mathieu Senoner, Pierre Trontin and Philippe Villedieu \\ ONERA - The French Aerospace Lab, F-31055 Toulouse, France
}

The present work attempts to improve existing erosion models for ice crystal icing (ICI) simulations. In particular, prior comparisons between experiments and numerical simulations highlighted two major limitations of current erosion models. First, the erosion rate does not explicitly depend on the size of the impinging particles in existing models while the influence of the size parameter has been clearly demonstrated in experimental icing test campaigns. Second, erosion rates are systematically underestimated when considering accretion occurring at high liquid water to total water contents, i.e. large ice crystal melting ratios. The present work proposes to partially remedy these limitations by accounting for fragmentation effects of the eroding particles during their impact, resulting in an explicit size dependency of the erosion rate on ice crystal size. The second limitation is somewhat mitigated by accounting for the weakening of the ice layer due to entrapped liquid water. A third improvement is related to a more accurate description of geometrical effects for ice mass removal induced by tangential particle impacts. The resulting modifications in erosion rate prediction are then implemented in the icing suite IGLOO2D. Comparisons of numerical accretion simulations based on the improved erosion model with experimental data of the literature confirm quantitative improvements with respect to existing erosion models.

\section{Nomenclature}

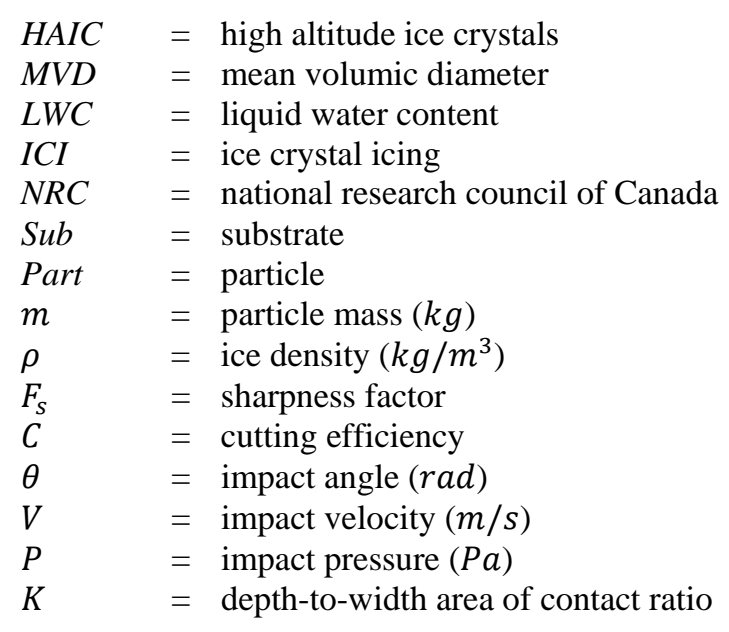




$\begin{array}{ll}R_{e l} & =\text { ice yield strength }(\mathrm{Pa}) \\ E & =\text { ice Young modulus }(\mathrm{Pa}) \\ v & =\text { ice Poisson ratio } \\ \varepsilon_{D} & =\text { deformation wear factor }\left(\mathrm{J} / \mathrm{m}^{3}\right)\end{array}$

\section{Introduction}

The mechanisms involved in ice crystal icing (ICI) are not yet fully understood and several research efforts are currently ongoing [1] to improve our knowledge on ICI and eventually improve the predictive capacities of numerical tools regarding ice accretion severity. A major phenomenon that drives ICI is the erosion caused by the impingement of ice crystals on accreted ice deposits. The present work pursues prior research efforts [2] to derive a semi-empirical erosion model for ICI simulation tools which improves well known limitations of models based on classic solid/solid collision theory [3] [4] [5] in the ICI context. It appears that in glaciated conditions, i.e. partially melted ice particles, standard erosion models only provide fair agreement with experimental data [6] for low liquid water content $(L W C)$ to total water content $(T W C)$ cases. On the contrary, current models are unable to predict the influence of ice crystal size on erosion and tend to systematically under predict erosion rates for large $L W C$ to $T W C$ ratios.

This paper is organized as follows: Part III briefly summarizes the principles of the standard erosion models of Finnie and Bitter and the erosion model proposed by the authors during prior work [2]. Part IV rewrites the particle momentum equations without the simplifying assumption of a constant depth-to-width area of contact ratio during impact in order to predict more accurate ice shapes. Part V deals with the calculation of particle's kinetic energy dissipated during impact using brittle material dynamic fracture theory [7] [8] and part VI with the influence of LWC on erosion rate. Finally, numerical simulations based on the improved erosion model are performed and compared to experimental data [9] [6] in part VII. The main findings of the present work are summarized in the conclusion.

\section{Summary of the semi-empirical model based on Finnie and Bitter theory}

This section presents a summary of the semi-empirical model described by Charton et al. [2] based on Finnie and Bitter solid/solid collision theory and adapted for ICI context. There is broad consensus in the community [10] [11] [12] [13] that erosion is driven by two main phenomena: cutting wear and deformation wear. Both are strongly dependent on the particle density, velocity and shape, as well as on the surface properties such as Young modulus, Poisson ratio, yield strength and hardness. Moreover, cutting wear is mostly driven by the velocity component tangential to the impinged surface and is more effective for ductile materials. On the contrary, deformation wear is mainly driven by normal velocity and is more effective for brittle bodies.

\section{A. Deformation and cutting wear phenomena}

According to Bitter [3], deformation wear is the consequence of the particle's kinetic energy being absorbed by the target during impact. As long as the maximum stress to which the material is locally subjected to does not exceed its yield strength, only elastic deformation occurs and no material is removed. However, if the yield strength of the target material is locally exceeded during collision, plastic deformation occurs in the regions of maximum stress, i.e. around the center of the contact area between particle and surface. Hence, a large number of particle impacts will form a plastically deformed surface with an increased hardness that may eventually lead to material failure due to the formation of inner lateral and radial cracks (Fig. 1).

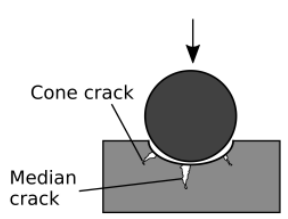

(a)

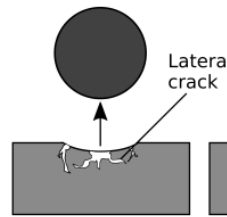

(b)

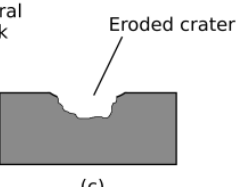

(c)

Fig. 1 Deformation erosion mechanism - (a) growth of cone crack and median crack, (b) closure of cracks, (c) eroded crater formed - Adapted from Parsi et al. [13] 
Based on the description of cutting wear by Finnie [5], Bitter proposed the following mechanism [4]: if impact energy allows the formation of a permanent indentation, the tangential component of the velocity will make that indentation larger and the sweeping action of the particle within the target will additionally pile up material around the crater. The piled-up material is then eventually removed by continuous particle impacts (Fig. 2). Finnie [5] and Arabnejad et al. [12] define two cutting regimes according to two boundary conditions for the end of the cutting action. In the first regime, cutting ceases when the particle can no longer move forward, i.e. when its tangential velocity component vanishes. In the second regime, the particle impinges with a sufficiently large tangential velocity component and at a sufficiently shallow angle to leave the surface after impact. Therefore, the particle's cutting behavior is defined by a critical impact angle.

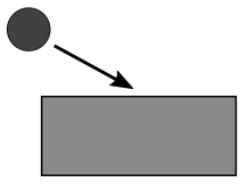

(a)

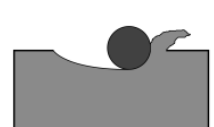

(b)

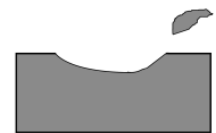

(c)

Fig. 2 Cutting erosion mechanism - (a) before the impact, (b) sweeping action and piling material, (c) separation of material from the surface - Adapted from Parsi et al. [13]

\section{B. Expressions of the eroded volumes}

The Hertzian elastic collision theory [3] is used to calculate the velocity $V_{e l}$ at which the elastic limit is just reached. Erosion occurs if the plastic deformation triggering condition is respected, thus if the particle normal velocity is higher than $V_{e l}$. Then, the resolution of energy and momentum balance leads to the deformation wear and cutting wear eroded volume expressions respectively noted $V_{o l} l_{D}$ and $V_{o l}$. Tab. 1 summarizes these expressions. The calculation of these expressions, as well as the detailed characterization of the parameters in ICI context can be found in [2].

Tab. 1 Summary of deformation and cutting wear expressions - Note: $V_{e l}=\frac{\pi^{2}}{2 \sqrt{10 \rho}} R_{e l}^{\frac{5}{2}}\left(\frac{1-v^{2}}{E_{\text {sub }}}+\frac{1-v^{2}}{E_{\text {part }}}\right)^{2}$

\begin{tabular}{|c|c|c|}
\hline Condition & Deformation wear & Cutting wear \\
\hline$V_{n}<V_{e l}$ & $\operatorname{Vol}_{D}=0$ & $\operatorname{Vol}_{C}=0$ \\
\hline$V_{n}>V_{e l}$ and $\theta \geq \arctan \left(\frac{K}{2}\right)$ & $\operatorname{Vol}_{D}=\frac{\frac{1}{2} m\left(V_{n}-V_{e l}\right)^{2}}{\varepsilon_{D}}$ & $\operatorname{Vol}_{C}=C \frac{m V^{2} \cos ^{2}(\theta)}{2 P}$ \\
\hline$V_{n}>V_{e l}$ and $\theta<\arctan \left(\frac{K}{2}\right)$ & $\operatorname{Vol}_{D}=\frac{\frac{1}{2} m\left(V_{n}-V_{e l}\right)^{2}}{\varepsilon_{D}}$ & $V o l_{C}=C \frac{2 m V^{2} \sin (\theta)(K \cos (\theta)-\sin (\theta))}{P K^{2}}$ \\
\hline
\end{tabular}

The following hypotheses were used to derive the relations summarized in table 2

1. Impinging particles are spherical

2. The energy dissipated by the particle is negligible: no particle fragmentation or plastic deformation occurs within the particle

3. Impact velocity is low enough, so that the energy dissipated as heat is negligible

4. The plastic initiation condition must be verified for the erosion phenomena to happen $\left(V_{n}>V_{e l}\right)$

5. The ratio of the depth-to-width contact area $K$ is constant during the impact (Fig. 4)

6. The volume eroded by deformation wear is equivalent to the crater volume, and the one eroded by cutting wear is equal to the swept volume by the particle during its contact with the body

However, some of these assumptions are probably invalid in the ICI context. First, particle sharpness may significantly alter the erosion effectiveness through stress concentration. Erosion caused by sand particle on metal plates was up to four times higher for fully sharp particles [12]. In the case of non spherical particle, as it is in ICI context, Arabnejad et al. [12] correct the hypothesis of spherical particles using the sharpness factor $F_{s}$. Charton et al. [2] proposed an expression for $F_{s}$ based on the observations of Arabnejad et al. [12]. 
Second, assumption 2 is not verified in the ICI context where most impacts occur in the so called severe or catastrophic fragmentation regime. In the present work, the classification of impact regimes is based on the nondimensional number L [14], defined as the ratio of kinetic energy to surface energy at the moment of impact. The threshold values delimiting the different regimes in the ICI context are based on the experiments of Hauk et al [15]. Values of $L \leq L_{1}=0.5$ characterize a quasi-elastic rebound without particle fragmentation, $L_{1} \leq L \leq L_{2}=90$ corresponds to inelastic rebound with minor particle fragmentation such as chipping while $L>L_{2}$ corresponds to a highly inelastic impact with major particle fragmentation. Considering the high impact velocities encountered in realistic engines, i.e. $80 \mathrm{~m} / \mathrm{s}$ and above, most impacts are assumed to occur in the severe or catastrophic fragmentation regime. Therefore, the energy dissipated by particle fragmentation should be accounted in the energy balance. . Section V is dedicated to the calculation of this energy and its influence on the erosion mass rate.

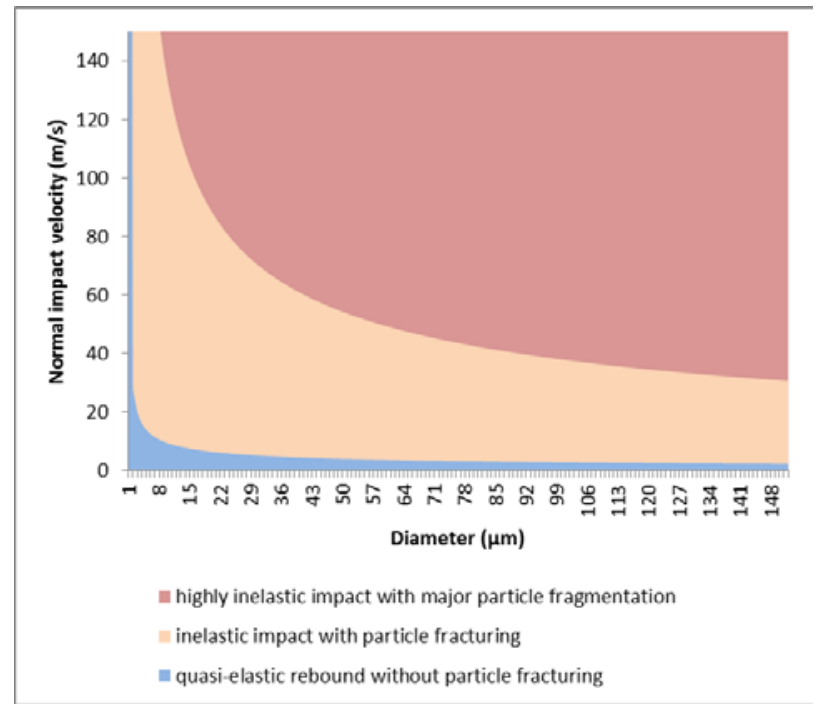

Fig. 3 Impact regimes function of normal velocity and particle diameter

Third, it will be shown in section IV that the equations of motion of the particle during impact may still be solved analytically for a non constant value of $\mathrm{K}$ and that relaxing this hypothesis helps improve predicted ice shapes in certain conditions.

The following sections propose to rewrite the erosion model relaxing assumptions 2 and 5 . Furthermore, the influence of the $L W C$ on erosion rate will be also accounted for.

\section{Non-constant depth-to-width area of contact ratio $K$}

The volume of target material eroded via the cutting mechanism is calculated by both Finnie [5] and Arabnejad et al. [12] using a constant ratio $K$ of contact area between particle and surface when the latter are projected respectively among the $\mathrm{x}$ - and $\mathrm{y}$-axes, i.e. $K=A_{y} / A_{x}=$ constant (Fig. 4). This assumption simplifies the resolution of particle momentum equations. As a result, the critical angle defining the particle cutting behaviour is dependent of the parameter $K$, which then serves as an adjustment constant for the model. ICI experiments of Currie and co-workers [9] [6] show two different accretion patterns: either a purely conical shape on the one hand or a cone on top of a cylinder, see Fig. 6 and Fig. 9 respectively. It will be shown that the evaluation of the volume removal by cutting with varying values of the parameter $K$ allows to reproduce the "cone on top of a cylinder" accretion shapes obtained at high Mach numbers.

The new expression for the volume removal by cutting is now presented. To this purpose, the impact of spherical particle of radius $R$ on a wall whose normal vector is oriented towards the y-axis, is considered. The particle's velocity vector forms an angle $\theta$ with the x-axis (Fig. 4). 

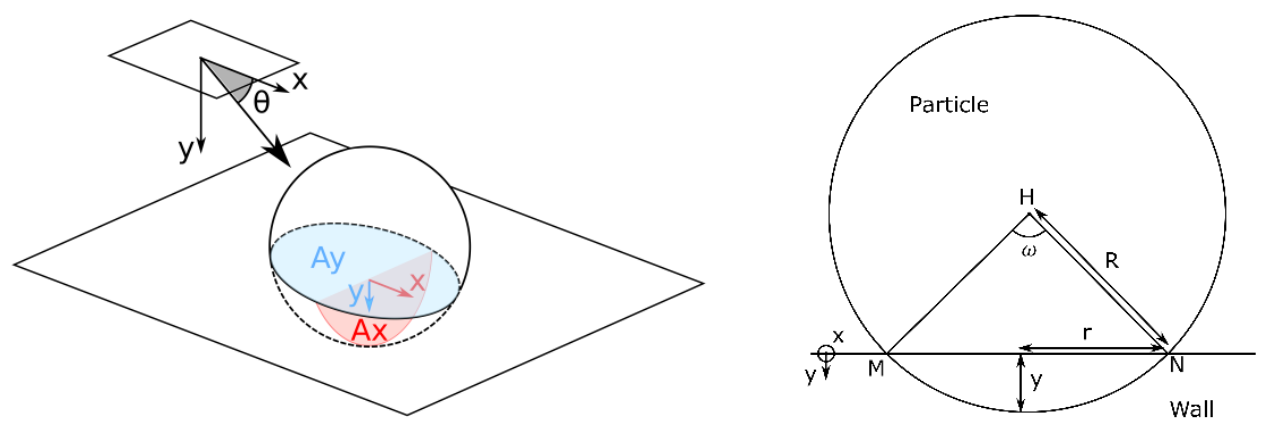

Fig. 4 Schematic of the projected surface areas $A_{x}$ and $A_{y}$ (left) - Geometrical variables (right)

The area of contact projected on the $y$ axis is given by:

$$
A_{y}=\pi r^{2}
$$

Where $r$ is the radius of the $y$ projected contact area. Hertz solid/solid collision theory and therefore Finnie and Bitter theory assume a low angle $\omega$. Assuming the indentation depth $y$ to be small with respect to the particle radius $R\left(\right.$ ), the contact radius may be approximated as $r^{2} \approx 2 R y$, yielding:

$$
A_{y}=2 \pi R y
$$

It is important to note, while remaining small, the indentation depth $y$ evolves during impact. $A_{x}$ is calculated as the area of the arc of the disk delimited by segments HN and HM, from which the area of the triangle HNM is subtracted:

$$
A_{x}=\frac{1}{2} \omega R^{2}-\frac{1}{2}(R-y) 2 r
$$

The assumption of a small indentation depth allows to equate the angle $\omega$ and its $\operatorname{sine}: \omega \approx \sin (\omega)=\frac{r}{R}$ Thus the area projection along $\mathrm{x}$-axis may be rewritten as:

$$
A_{x}=r y=y^{3 / 2} \sqrt{2 R}
$$

Hence, the ratio $K=A_{y} / A_{x}$ is not constant during the cutting action and evolves with the inverse square root of the indentation depth:

$$
K=\frac{2 \pi R}{\sqrt{2 y R}}
$$

The expression of the eroded volume by cutting wear can be written without the assumption of a constant area ratio $K$. This volume $\mathrm{Vol}_{C}$ is defined as the volume swept by the surface $A_{x}$ during the collision time $t_{c}$. Hence, defining $x_{c}$ the abscissa where cutting stops, $\operatorname{Vol}_{C}$ can be calculated as:

$$
\operatorname{Vol}_{C}=\int_{0}^{x_{C}} A_{x} d x=\int_{0}^{t_{c}} A_{x} x^{\prime}(t) d t
$$

In order to obtain an expression of the surface $A_{x}$, equations of the particle motion first written by Finnie et al. [5] can be resolved:

$$
\begin{aligned}
& m \frac{d^{2} x}{d t^{2}}+P A_{x}=0 \\
& m \frac{d^{2} y}{d t^{2}}+P A_{y}=0
\end{aligned}
$$

Where $P$ is the impact pressure which is equivalent to the yield strength of the material since the plastic initiation condition is assumed to be verified over the entire contact surface. Using equation (7) $A_{x}$ is given by:

$$
\operatorname{Vol}_{C}=-\frac{m}{P} \int_{0}^{t_{c}} x^{\prime \prime}(t) x^{\prime}(t) d t
$$


Partial integration gives: $\int_{0}^{t_{c}} x^{\prime \prime}(t) x^{\prime}(t) d t=\frac{1}{2}\left[x^{\prime}(t)^{2}\right]_{0}^{t_{c}}$, hence the expression of the eroded volume by cutting action is given by:

$$
\operatorname{Vol}_{C}=\frac{m}{2 P}\left(x^{\prime}(0)^{2}-x^{\prime}\left(t_{c}\right)^{2}\right)
$$

Where $x^{\prime}(0)$ is the particle tangential velocity at the beginning of the impact, and $x^{\prime}\left(t_{c}\right)$ at the end of the cutting action. According to Finnie, two scenarios describe the end of the cutting action:

1. The particle is stopped in the body and has no more tangential velocity at the end of the cutting action: $x^{\prime}\left(t_{c}\right)=0$

2. The particle leaves the surface: $y\left(t_{c}\right)=0$

The first scenario governs impacts at a quasi-normal angle. Given the boundary condition $x^{\prime}\left(t_{c}\right)=0$, the expression of the eroded volume considering an impacting rate $\dot{m}_{i m p}$ is:

$$
\operatorname{Vol}_{C 1}=\frac{\dot{m}_{\text {imp }} V^{2} \cos (\theta)^{2}}{2 P}
$$

This expression is the same as the one found by Arabnejad et al. [12]. For low impact angle cases, $x^{\prime}\left(t_{c}\right)$ can be expressed as:

$$
x^{\prime}\left(t_{c}\right)=x^{\prime}(0)+\int_{0}^{t_{c}} x^{\prime \prime}(t) d t=x^{\prime}(0)-\frac{P}{m} \int_{0}^{t_{c}} A_{x} d t=x^{\prime}(0)-\frac{P \sqrt{2 R}}{m} \int_{0}^{t_{c}} y(t)^{3 / 2} d t
$$

Where $y(t)$ is given by the solution of equation (8): $y(t)=\frac{V \sin (\theta)}{\beta} \sin (\beta t)$, and $\beta=\sqrt{\frac{2 \pi R P}{m}}$. Thus:

$$
x^{\prime}\left(t_{c}\right)=V \cos (\theta)-\frac{P \sqrt{2 R}}{m}\left(\frac{V \sin (\theta)}{\beta}\right)^{3 / 2} \int_{0}^{t_{c}} \sin (\beta t)^{3 / 2} d t
$$

The boundary condition of the second scenario is $y\left(t_{c}\right)=0$. The time $t_{c}$ is then given by the first non null time satisfying the boundary condition: $t_{c}=\frac{\pi}{\beta}$. Using the substitution $\beta t=\tau$, one obtains:

$$
x^{\prime}\left(t_{c}\right)=V \cos (\theta)-\frac{P \sqrt{2 R}}{m} \frac{(V \sin (\theta))^{3 / 2}}{\beta^{5 / 2}} \int_{0}^{\tau_{c}} \sin (\tau)^{3 / 2} d \tau
$$

The numerical resolution of $\int_{0}^{\tau_{c}} \sin (\tau)^{3 / 2} d \tau$ gives 1.75 , thus the tangential velocity at the end of the cutting action in the scenario of a low impact angle is given by:

$$
x^{\prime}\left(t_{c}\right)=V \cos (\theta)-1.75 \frac{V^{3 / 2} \sin (\theta)^{3 / 2} \rho^{1 / 4}}{6^{1 / 4} \pi P^{1 / 4}}
$$

The limit angle $\theta_{\text {lim }}$ that defines the impact regime as quasi-normal or as low angle is given by the solution of:

$$
V \cos \left(\theta_{\text {lim }}\right)-1.75 \frac{V^{\frac{3}{2}} \sin \left(\theta_{\text {lim }}\right)^{\frac{3}{2}} \rho^{\frac{1}{4}}}{6^{\frac{1}{4}} \pi P^{\frac{1}{4}}}=0
$$

When $V \cos \left(\theta_{\text {lim }}\right)<1.75 \frac{V^{\frac{3}{2}} \sin \left(\theta_{\text {lim }}\right)^{\frac{3}{2}} \rho^{\frac{1}{4}}}{6^{\frac{1}{4}} \pi P^{\frac{1}{4}}}$, the final particle velocity is 0 and we find the equation (10). Finally, the expression of the eroded volume by cutting wear, which verifies the two possible scenarios, is given by:

$$
\operatorname{Vol}_{C}=\frac{\dot{m}_{i m p}}{2 P}\left[V^{2} \cos ^{2}(\theta)-\max \left(0,\left(V \cos (\theta)-1.75 \frac{V^{\frac{3}{2}} \sin (\theta)^{\frac{3}{2}} \rho^{\frac{1}{4}}}{6^{\frac{1}{4}} \pi P^{\frac{1}{4}}}\right)^{2}\right)\right]
$$

This expression differs from the one established by Charton et al. [2] and recalled in table (Tab. 1). Equation (16) shows that the limit angle separating the cutting regimes is dependent on particle velocity and density as well as ice layer property as the impact pressure $P$ is equivalent to the compressible yield strength of the ice layer. As a result, the maximum eroded volume is not obtained for the same impact angle. While the maximum erosion was reached for a very low impact angle assuming a constant value $K$, it is reached for an intermediate value with expression (17). This is consistent as the very low impact angle case will give a higher final tangential velocity and thus less erosive power. Simulation results obtained with this new expression for cutting erosion will be discussed in section VII. 


\section{Energy dissipated by the particle fracturing/fragmentation}

The impact conditions encountered in ICI for realistic engines, i.e. with velocities of the order of $100 \mathrm{~m} / \mathrm{s}$ and particle diameters of the order of $50 \mu \mathrm{m}$, imply particle fragmentation during impact (Fig. 3). The fragmentation dissipates part of the kinetic energy prior to impact $Q_{c}$ and this energy sink needs to be taken into account in the particle's energy conservation equation. As a consequence, the less energy is available for ice layer erosion. In order to take this effect into account, a reduced velocity $V_{r}$ is used instead of the particle impact velocity. This allows us to calculate the eroded volume using the approach of Finnie and Bitter outlined in section IV while considering the energy dissipated during fragmentation. $V_{r}$ is defined as:

$$
V_{r}=V\left(1-\frac{Q_{f}}{Q_{c}}\right)^{0.5}
$$

The definition and calculation of $Q_{f}$ will be described in the final version of the paper

The influence of this additional energy sink on numerical results is discussed in section VII.

\section{Effect of liquid water content on erosion rate}

The experimental study of Currie et al. [6] showed that above a certain threshold, icing severity decreases with increasing ice crystal melting ratio (right section of the so-called melting plateau effect). As a matter of fact, the presence of liquid water is very essential for the accretion process in ICI condition. Inside jet engines, while entirely solid ice crystals would bounce on engine walls, a partially melt ice crystal may stick to the wall and initiate the accretion process. However, icing severity appears to decrease for high liquid water ratios. It is commonly assumed that too little liquid water content prevents the crystals to stick to the walls, while the upper limit of the plateau is a result of too few ice particles to cool the surface sufficiently to initiate accretion. However, an extended Messinger balance [16] alone is not able to predict this effect. Therefore, the latter must be modeled via a mechanism other than an energy balance. In ICI glaciated conditions, it may be assumed as a first approximation that the melting ratio ( $L W C$ to $T W C$ ) of the incoming particles is comparable to the final composition of the accreted ice as the wall eventually reaches an equilibrium temperature with the accreted ice (unheated wall). The empirical erosion model proposed by Trontin et al. [16] accounts for the dependency of the erosion rate on the quantity of liquid water trapped inside the ice layer. This section aims to enhance the semi-empirical erosion model of Finnie and Bitter with such liquid water dependence. Indeed, the ice layer's structural parameters should depend on the composition of the ice layer, in particular the water to ice ratio. If the liquid water content within the ice layer is assumed to be dictated by the layer's porosity, then the structural weakening of the layer may be directly inferred from this quantity. Stanislav et al. [17] or Mojtaba [18] showed that the ice's compressive strength and its Young modulus decrease as the volume occupied by air voids within the studied ice samples increases (Fig. 5). However, the ice samples studied were not obtained from ice crystal accretion. Since the material properties of laboratory ice may significantly differ from realistic accretion ice, a simple law calibrated on NRC experiments will be adopted in order to roughly model the evolution of the ice's structural properties with liquid water content. Therefore, the Young modulus and the compressive yield strength of the accreted ice layer become functions of liquid water saturation, which is defined as the mass of liquid water that has not ran back over the total layer mass.

$$
\begin{aligned}
E_{\Phi} & =E \times f\left(\alpha_{l}\right) \\
R_{e l, \Phi} & =R_{e l} \times f\left(\alpha_{l}\right)
\end{aligned}
$$

With $\alpha_{l}$ the liquid volume fraction and where:

$$
f\left(\alpha_{l}\right)=1.5-4.0 \alpha_{l}
$$

The fraction of liquid water entrapped within the ice layer is given by Messinger's conservation equations for solid and liquid $\dot{m}_{a c c s}$ and $\dot{m}_{a c c L}$ :

$$
\alpha_{l}=\frac{\dot{m}_{a c c L}}{\dot{m}_{a c c L}+\dot{m}_{a c c S}}
$$

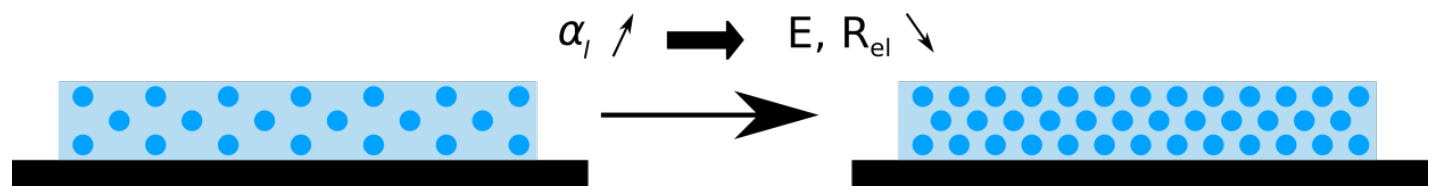

Fig. 5 Scheme of ice layer structure evolution with liquid water increase 
Using the corrected definitions of $E$ and $R_{e l}$ depending on $\alpha_{l}$, erosion rates are calculated with a weakened ice layer for high melting ratio cases. This allows to simulate ice accretion at high melting ratio conditions using the approach of Finnie and Bitter. Results are further discussed in section VII.

\section{Result with NRC experiment}

This section shows the simulation results of several experimental test campaigns performed by Currie and coworkers [9] [6]. These data is divided into five categories:

1. Series 1 (Run 17, 77, 67, 92, 101) characterizes the influence of particle melting ratio $Y_{l}$ at constant Mach number $M=0.25$ and constant mean volumetric particle diameter $M V D=45 \mu m$ when considering accretion on a crowned cylinder profile

2. Series 2 (Run 233, 238, 243, 248) shows the influence of the melting ratio $Y_{l}$ for a higher Mach number $(M=0.40)$ keeping the same $M V D$ and the same profile with respect to series 1

3. Series 3 (Run 1286) reproduces the operating conditions of series $1(M=0.25, M V D=45 \mu \mathrm{m})$ but for a hemispherical profile

4. Series 4 (Run 699) characterizes accretion for the hemispherical profile at a higher Mach and a lower mean volumic diameter $(M=0.40$ and $M V D=28 \mu \mathrm{m})$ compared to series 3

5. Finally, series 5 (Run 754) is run at conditions comparable to series $4(M=0.47$ and $M V D=28 \mu m)$ but with a wedge airfoil profile

The Mean Volumic Diameter, Mach number, melting ratio and test profiles for each series are summarized in Tab. 2. The simulation of these different test cases allows to assess the predictive capacities of the erosion model in presence of particle diameter, impact angle, Mach number and liquid water content variations. Appendix A (Appendix will be written for the final version of the paper) presents all the test cases in detail.

Tab. 2 Test matrix table

\begin{tabular}{|l|l|l|l|l|}
\hline Series & Mach & MVD & Yl & Test article \\
\hline $1(17,77,67,92,101)$ & 0.25 & $45 \mu \mathrm{m}$ & From 6.0 to 31.4\% & Crowned Cylinder \\
\hline $2(233,238,243,246)$ & 0.40 & $45 \mu \mathrm{m}$ & From 8.6 to 21.4 \% & Crowned Cylinder \\
\hline $3(1286)$ & 0.25 & $45 \mu \mathrm{m}$ & $7.0 \%$ & Hemispherical \\
\hline $4(699)$ & 0.40 & $28 \mu \mathrm{m}$ & $14.0 \%$ & Hemispherical \\
\hline $5(754)$ & 0.47 & $28 \mu \mathrm{m}$ & $14.1 \%$ & Wedge Airfoil \\
\hline
\end{tabular}

\section{A. Series 1 - Influence of LWC for low Mach and high MVD with Crowned Cylinder test article}

Series 1 shows the influence of $Y_{l}$ on accretion rate for $M=0.25$ and $M V D=45 \mu \mathrm{m}$. Charton et al. [2] obtained good agreement for the lowest $Y_{l}$ case (Run 17, $Y_{l}=6 \%$ ) using Finnie and Bitter's model. However, their model did not account for influence of the melting ratio on erosion rates and would therefore yield to overestimate the accretion severity for high melting ratio cases as the sticking efficiency increases and the erosion rates are the same. The proposed corrections for the Young modulus and the compressive Yield strength of the ice layer according to the layer's local porosity, allow to simulate cases with high melting ratios. Erosion increases towards higher melting ratios due to weakening of the ice layer. Fig. 6 presents the simulation results of Run $17\left(Y_{l}=6 \%\right)$, Run 77 $\left(Y_{l}=11.2 \%\right)$, Run $67\left(Y_{l}=16.6 \%\right)$, Run $92\left(Y_{l}=26.4 \%\right)$ and Run $101\left(Y_{l}=31.4 \%\right)$. Results will evolve and will be further discussed in the final paper. 


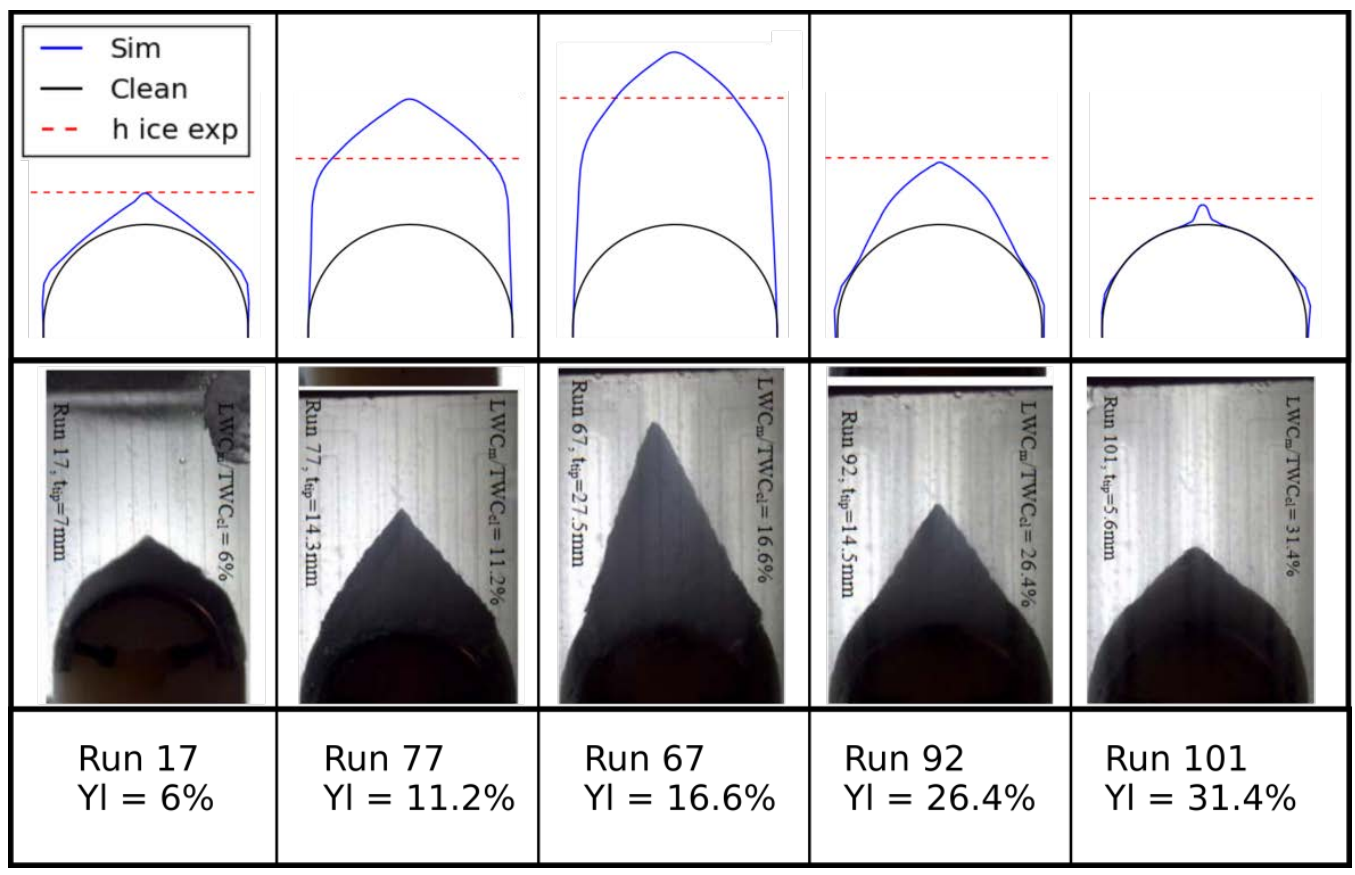

Fig. 6 Series 1 ice shape simulations (up) and experimental observations (down) from Currie et al. [6]

\section{B. Series 2 - Influence of LWC for high Mach and high MVD with Crowned Cylinder test article} Results will evolve and will be further discussed in the final paper.

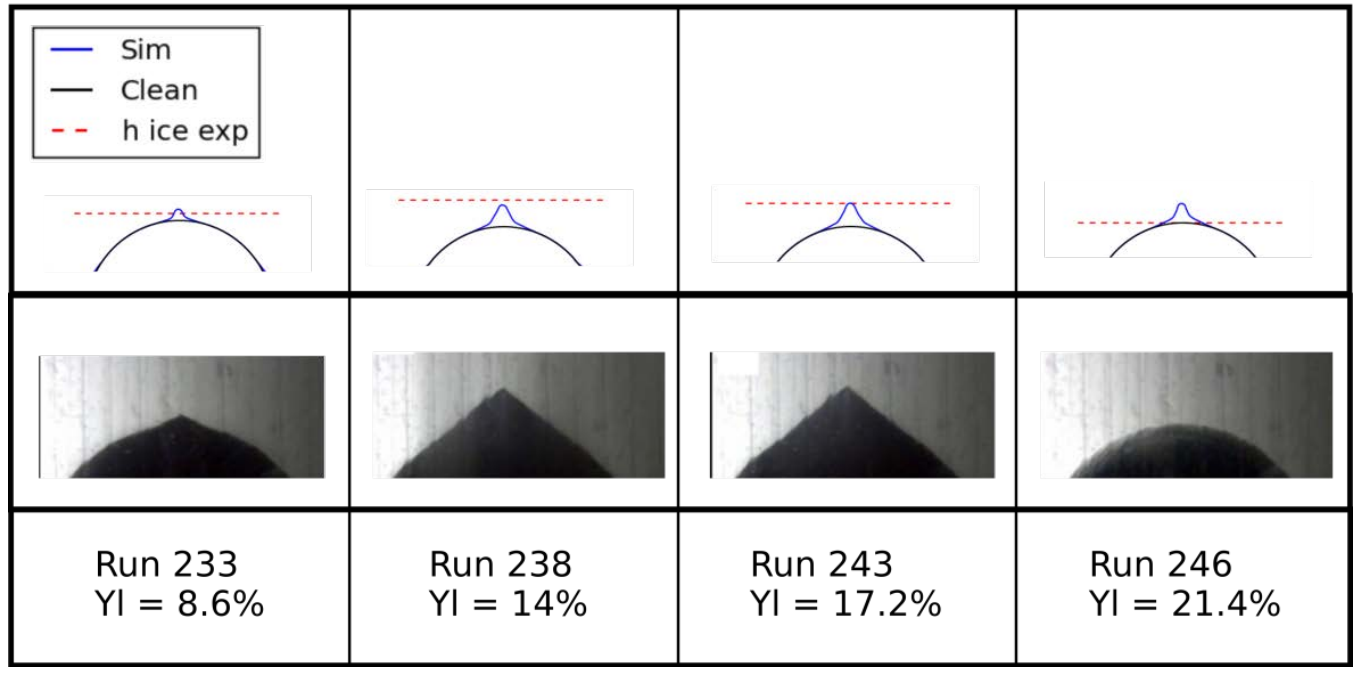

Fig. 7 Series 2 ice shape simulations (up) and experimental observations (down) from Currie et al. [6]

\section{Series 3 - Low Mach and high MVD with Hemispherical test article}

Series 3 is a single test case (Run 1286) realized under the same aerodynamic and dispersed phase conditions as Run 17 of series 1 . However, the overall impact angle is different since the geometry of the profile is a hemispherical nose with a lower chord. The simulation of this test case will show the reliability of the model for similar conditions, and will allow us to better discuss the simulation results of series 4 , also performed with the hemispherical profile but for smaller particles and a higher Mach. Results will evolve and will be further discussed in the final paper. 


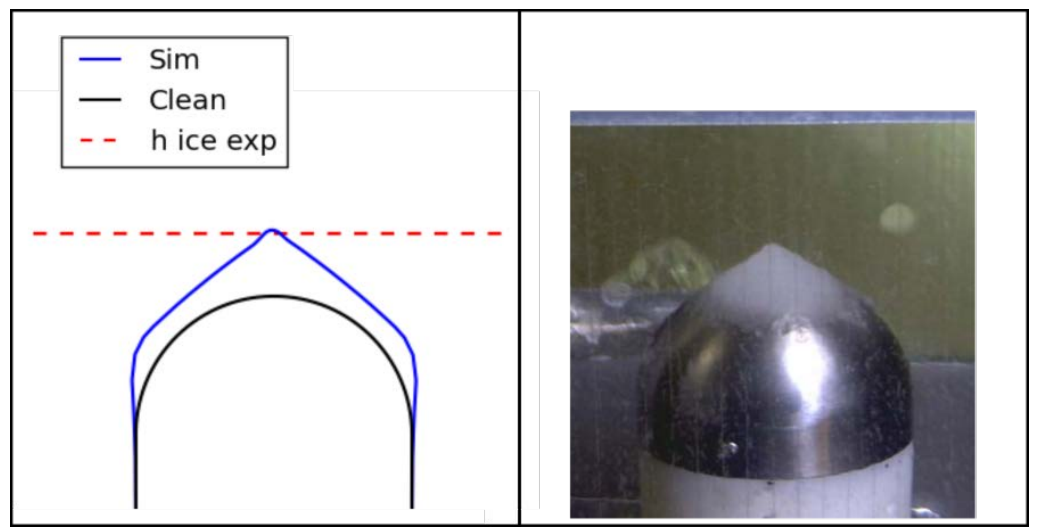

Fig. 8 Run 1286 ice shape simulation (left) and experimental observation (right) from Currie et al. [19]

\section{Series 4 - High Mach and low MVD with Hemispherical test article}

Series 4 is a single test case (Run 699) realized with the hemispherical profile for a higher Mach and a lower $M V D$ compared to Series $3(M=0.4$ and $M V D=28 \mu m)$. Erosion rates are miss-predicted by existing erosion models [2] [16] [20] as they do not explicitly account for the influence of the particle diameter. However, accounting for energy dissipated by particle fragmentation during impact yields fair agreement with experimental data (Fig. 9). The rewriting of erosion equations without the simplifying assumption of parameter constant geometrical factor $K$ enables to correctly predict the accreted ice shape, namely a conical shape on top of a cylindrical basis. Results will evolve and will be further discussed in the final paper.

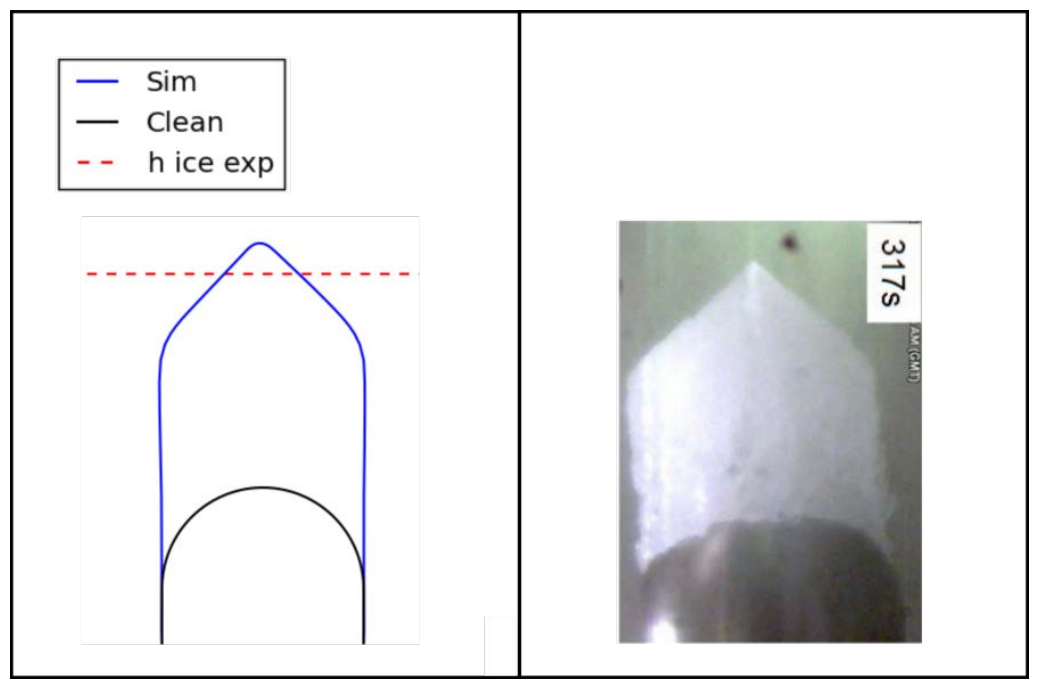

Fig. 9 Run 699 ice shape simulation (left) and experimental observation (right) from Currie et al. [9]

\section{E. Series 5 - High Mach and low MVD with Wedge Airfoil test article}

Series 5 is a single test case (Run 754) with the same test conditions as Series 4 but for the Wedge Airfoil geometry which displays a conical angle of attack. This test case allows to assess the erosion model for a different impact angle. Figure 10 presents the simulation results. Ice height and shape are in good agreement with experimental data, and the "tongue" growth observed by Currie et al. [9] which gives the conical shaped ice tip is also predicted numerically. Results will evolve and will be further discussed in the final paper. 


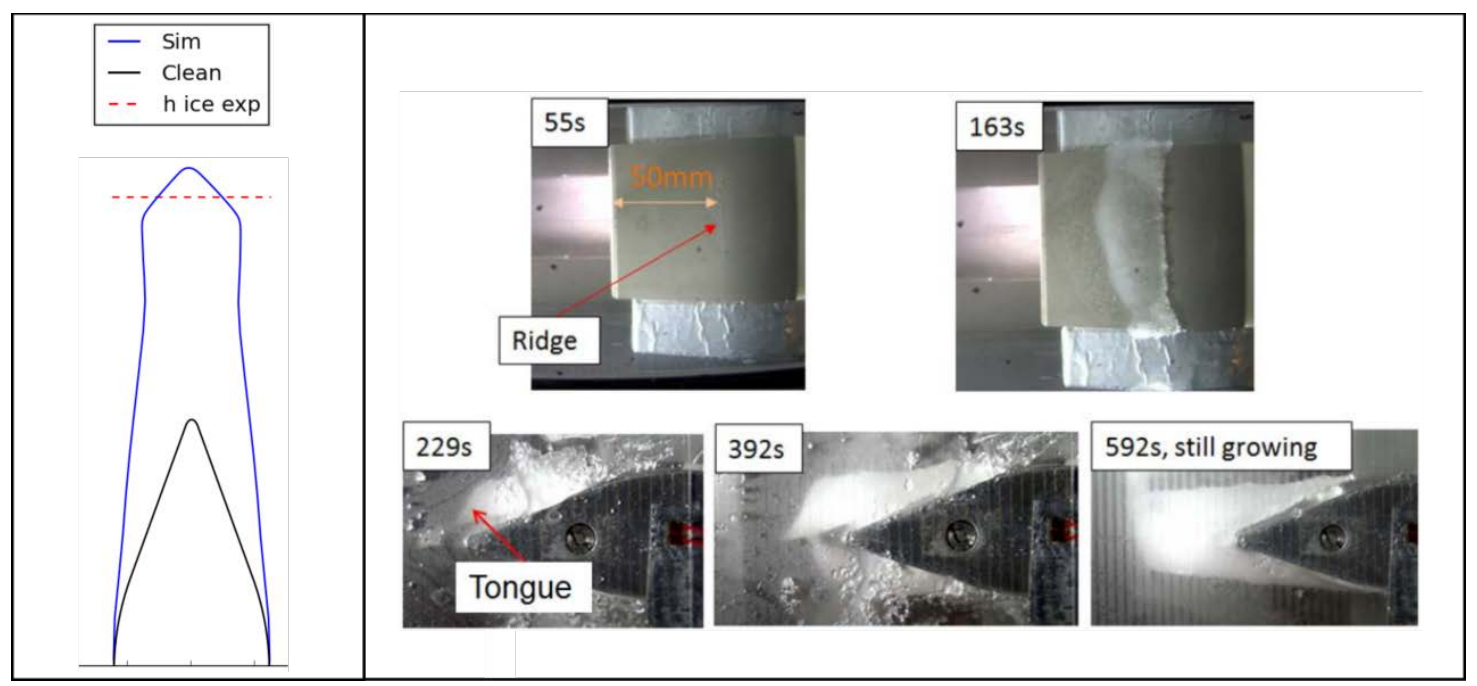

Fig. 11 Run 754 ice shape simulation (left) and experimental observation (right) from Currie et al. [9]

\section{Conclusion}

This part will be written is the final paper

\section{Appendix}

This part will be written is the final paper

\section{Acknowledgments}

This work is conducted in the scope of a PhD thesis in cooperation between ONERA and SAFRAN AIRCRAFT ENGINES (Safran Group). The first author gratefully acknowledges the ANRT (Association Nationale de la Recherche et de la Technologie) for its financial support.

\section{References}

[1] E. Commission, "MUSIC-haic," H2020, [Online]. Available: https://ec.europa.eu/inea/en/horizon2020/projects/h2020-transport/aviation/music-haic. [Accessed November 2018].

[2] V. Charton, P. Trontin, G. Aouizerate and P. Villedieu, "Semi-Empirical Modelling of Erosion Phenomena for Ice Crystal Icing Numerical Simulation," SAE International, 2019.

[3] J. Bitter, "A study of erosion phenomena - Part I," Koninklijke, Shell-Laboratorium, Amsterdam, 1962.

[4] J. Bitter, "A study of erosion phenomena - Part II," Koninklijke, Sheil-Laboratorium, Amsterdam, 1962.

[5] I. Finnie and D. McFadden, "On the velocity dependence of the erosion of ductile metals by solid particles at low angles of incidence," Wear, 1978.

[6] T. C. Currie, D. Fuleki and A. Mahallati, "Experimental Studies of Mixed-Phase Sticking Efficiency for Ice Crystal Accretion in Jet Engine," 6th AIAA - Atmospheric and Space Environments Conference, 2014.

[7] D. Grady and M. Kipp, "Continuum Modelling of Explosive Fracture in Oil Shale," Int. J. Rock Mech, Sci \& Geomech, vol. 17, p. 147 to 157, 1980.

[8] P. Forquin and B. Erzar, "Dynamic fragmentation process in concrete under impact and spalling tests," Int. J. Fract. , pp. 193-215, 2010.

[9] T. C. Currie and D. Fuleki, "Experimental Results for Ice Crystal Icing on Hemispherical and Double Wedge Geometries at Varying Mach Numbers and Wet Bulb Temperatures," 8th AIAA - Atmospheric and Space Environments Conference, 2016.

[10] I. Hutchings, "A model for the erosion of metals by sherical particles at normal incidence," University of Cambridge, Department of Metallurgy and Materials Science, 1981. 
[11] C. Huang, S. Chiovelli, P. Minev, J. Luo and K. Nandakumar, "A comprehensive phenomenological model for erosion of materials in jet flow," Powder Technology, 2008.

[12] H. Arabnejad, A. Mansouri, S. Shirazi and B. McLaury, "Development of mechanistic erosion equation for solid particles," Wear, 2015.

[13] M. Parsi, K. Najmi, F. Najafifard, S. Hassani, B. S. McLaury and S. A. Shirazi, "A comprehensive review of solid particle erosion modeling for oil and gas wells and pipelines applications," Journal of Natural Gas Science and Engineering, 2014.

[14] G. Vidaurre and J. Hallett, "Particle Impact and Breakup in Aircraft Measurement," Journal of Atmospheric and Oceanic Technology, vol. 26, 2008.

[15] T. Hauk, I. Roisman and C. Tropea, "Investigation of the Impact Behaviour of Ice Particles," in AIAA Aviation, 6th Atmospheric and Space Environments Conference, Atlanta, 2014.

[16] P. Villedieu, P. Trontin and R. Chauvin, "Glaciated and mixed-phase ice accretion modeling using ONERA 2D icing suite," 6th AIAA - Atmospheric and Space Environments Conference, 2014.

[17] S. I. Rogachko, G. N. Evdokimov, M. V. Melnikov, T. Karna and L. Eila, "The Influence of Porosity on Mechanical Strength of Hummocks," in Proc. 16th Int. Conf. Offshore Mechanics and Artic Engineering, Yokohama, 1997.

[18] M. Eskandarian, "Ice shedding from overhead lines by mechanical breaking," University of Quebec, 2005.

[19] T. C. Currie, D. Fuleki, D. C. Knezevici and J. D. MacLeod, "Altitude scaling of Ice Crystal Accretion," in 5th AIAA Atmospheric and Space Environments Conference, San Diego, 2013.

[20] A. Baumert, S. Bansmer, P. Trontin and P. Villedieu, "Experimental and numerical investigations on aircraft icing at mixed phase conditions," International Journal of Heat and Mass Transfer, 2018.

[21] E. Commission, "HAIC," 2013-2016. [Online]. Available: http://www.haic.eu/. [Accessed 2018].

[22] D. C. Knezevici, D. Fuleki, T. C. Currie and J. MacLeod, "Particle Size Effects on Ice Crystal Accretion," 4th AIAA Atmospheric and Space Environments Conference, 2012.

[23] D. C. Knezevici, D. Fuleki, T. C. Currie, B. Galeote, J. Chalmers and J. MacLeod, "Particle Size Effects on Ice Crystal Accretion - Part II," 5th AIAA - Atmospheric and Space Environments Conference, 2013. 